\title{
Ege Üniversitesi Tıp Fakültesi veri tabanındaki kolorektal kanserli olguların epidemiyolojik ve genel sağ kalım özellikleri
}

\section{Epidemiologic and survival characteristics of patients with colorectal cancer in Ege University medical faculty database}

\author{
Nalan Gülşen Ünal ${ }^{1}$ \\ Başak Doğanavşargil ${ }^{4,5}$ \\ Gizem Coşgun² \\ Burcu Çakar ${ }^{6}$ \\ Fatma Sert ${ }^{2}$ \\ Erhan Akgün ${ }^{3}$ \\ Murat Sezak ${ }^{4}$ \\ Halit Osmanoğlu ${ }^{3}$ \\ Mustafa Korkut ${ }^{3}$ \\ Serdar Özkök ${ }^{2}$ \\ Tayfun Yoldaş ${ }^{3}$ \\ Ayfer Haydaroğlu ${ }^{2}$ \\ Ahmet Ömer Özütemiz ${ }^{1}$ \\ Deniz Yalman ${ }^{2}$ \\ Cemil Çalışkan $^{3}$ \\ ${ }^{1}$ Ege Üniversitesi Tıp Fakültesi, Gastroenteroloji Bilim Dalı, İzmir, Türkiye \\ ${ }^{2}$ Ege Üniversitesi Tıp Fakültesi, Radyasyon Onkolojisi Anabilim Dalı, İzmir, Türkiye \\ ${ }^{3}$ Ege Üniversitesi Tıp Fakültesi, Genel Cerrahi Anabilim Dalı, İzmir, Türkiye \\ ${ }^{4}$ Ege Üniversitesi Tıp Fakültesi, Patoloji Anabilim Dalı, İzmir, Türkiye \\ ${ }^{5}$ Ege Üniversitesi Tıp Fakültesi, Kanserle Savaş Araştırma ve Uygulama Merkezi, İzmir, Türkiye \\ ${ }^{6}$ Ege Üniversitesi Tıp Fakültesi, Medikal Onkoloji Bilim Dalı, İzmir, Türkiye
}

Öz

Amaç: Kolorektal kanser (KRK) epidemiyolojisi ve genel sağ kalım (GSK) özelliklerinin araştırılmasıdır.

Gereç ve Yöntem: Ege Üniversitesi Kanserle Savaş Uygulama ve Araştırma Merkezine (EÜKAM) 1992-2017 yıllarında kayıtlı Ege Üniversitesi Tıp Fakültesi kanser verileri retrospektif olarak taranmıştır. CANREG özel bilgisayar programına kayıtlı veriler, WHO ve SEER sistemlerinde gruplanarak analizler yapılmıştır. İstatistiksel analizlerde Ki-kare, General Linear Model (GLM), Kaplan-Meier sağ kalım analizleri kullanılmıştır. Yerel etik kurul onayı alınmıştır.

Bulgular: Toplam 117.139 kanser olgusunun 7.285 'i $(\% 6,2)$ KRK'dir. KRK sıklığı, tüm olgular içinde yedinci sırada saptanmıştır. Olguların 4.330'u (\%59) erkektir. Rektum yerleşimi, \%38,4 olguda saptanmış olup, en sık lokalizasyondur. KRK yaşla artmaktadır; 60 yaş ve üzerinde her iki cinsiyette de anlamlı artış saptanmıştır $(p=0,022)$; cinsiyetler arası fark anlamlı değildir $(p=0,299)$. KRK'de yıllara göre doğrusal artış toplamda anlamlıdır (GLM: $F=12,349 ; \quad p<0,0001$ ). Olguların \%86'sı adenokarsinomdur, \%54,2'si lokal ileri evrede tanı almıştır. Lokal ileri evrede beş yıllık GSK \%66,4 iken, uzak metastaz varlığında \%15,8'e düşmektedir ( $p<0,0001)$. Medyan sağ kalım 69 ay, beş ve 10 yıllık GSK oranları sırasıyla \%53 ve \%40'tır. On yıllık GSK oranı kadınlarda istatistiksel olarak anlamlı yüksektir. Yetmiş yaş ve üstü, beş ve 10 yıllık GSK oranları istatistiksel olarak anlamlı düşüktür, 20-29 yaş olgularda GSK, 70 yaş ve üstü dikkate alınmazsa anlamlı düşük bulunmuştur $(p<0,0001)$.

Sonuç: Hastanemizde yıllara göre KRK'de artış vardır, tanı genellikle lokal ileri evrede konulmuştur. En sık görülme yaşı olan 60-69 yaş grubunda beş yıllık GSK \%54,5'dir. On yıllık GSK kadınlarda $\% 43,3$ olup erkeklerden daha yüksektir. Prognozda histoloji ve evre en belirleyici parametrelerdir.

Anahtar Sözcükler: Kolorektal kanser, epidemiyoloji, mortalite, sağ kalım.

\section{Abstract}

Aim: The aim of this study was to determine epidemiological and overall survival (OS) characteristics of colorectal cancer (CRC) patients.

\footnotetext{
Yazışma Adresi: Nalan Gülşen ÜNAL

Ege Üniversitesi Tıp Fakültesi İç Hastalıkları Anabilim Dalı

Gastroenteroloji Bilim Dalı, İzmir, Türkiye

E-mail:drnalanunal@gmail.com
} 
Materials and Methods: Data of Ege University Cancer Control and Research Center between 19922017 were screened retrospectively. Data recorded in CANREG program were grouped and analyzed in WHO and SEER systems. Chi-square test, General Linear Model (GLM) and Kaplan-Meier survival analysis were used for statistical analysis.

Results: Number of CRC cases were 7285 (6.2\%) among 117139 cancer cases. CRC ranked 7th among all the cancer types. Of the CRC patients, 4330 (59\%) were male. The most common localization was rectum (38.4\%). CRC increases with age. A significant increase was found at the age of 60 years and older $(p=0.022)$ among both genders, but the difference between genders was not significant $(p=0.299)$. Linear increase over the years was significant in total (GLM: $F=12,349$; $p<0.0001)$. Adenocarcinoma (86\%) was the most common histologic type, $54.2 \%$ of patients were diagnosed at locally advanced stage. The 5-year OS rate was $66.4 \%$ in locally advanced cancer and $15.8 \%$ in case of distant metastasis $(p<0.0001)$. Median survival was 69 months, 5 and 10-year OS rates were $53 \%$ and $40 \%$ respectively. Ten-year OS was significantly higher in women. Five and $10-$ year OS rates were significantly lower in $\geq 70$-year-old age group, and subsequently in the 20-29 years age group if $\geq 70$-year-old age group was not taken into account $(p<0.0001)$.

Conclusion: There is an increase in CRC over the years, and generally the patients were diagnosed in locally advanced stages. The 5-year OS rate was 54.5\% in the 60-69 age group which accounts for the most common age group, Ten-year OS rate was $43.3 \%$ in women which was higher than in men. Histology and stage were the most important prognostic parameters in prognosis.

Keywords: Colorectal ancer, epidemiology, mortality, overall survival.

\section{Giriş}

Kolorektal kanserler (KRK), tüm dünyada morbidite ve mortaliteye sebep olan kanser türleridir. İnsidans ve mortalite oranları tüm dünyada değişkenlik göstermektedir. Küresel olarak, Dünya Sağlık Örgütü GLOBOCAN 2018 verilerine göre, KRK insidans bakımından üçüncü, mortalite açısından ikinci sırada yer almaktadır (1). 2018'de yaklaşık 1,8 milyon yeni vaka ve 881.000 ölüm tahmin edilmiştir (1). Avrupa'da (örneğin; Macaristan, Slovenya, Slovakya, Hollanda ve Norveç), Avustralya, Yeni Zelanda, Kuzey Amerika ve Doğu Asya'da (özellikle Japonya, Kore, Singapur) insidans yüksek iken, gelişmekte olan ülkelerde özellikle Afrika ve Asya'da düşük oranlar bildirilmiştir (1). KRK insidansındaki farklılıkların genetik ve çevresel faktörlerle ilişkili olduğu düşünülmektedir (2). Batı tarzı beslenme, işlenmiş et, alkollü içecekler, obezite, erkek cinsiyet artmış KRK riskiyle ilişkili bulunmuştur. Ancak, KRK gelişiminde en önemli risk faktörleri yaş ve genetiktir (3). Kırk yaş altı sporadik KRK nadirken, 40-50 yaş sonra insidansı artmaya başlamaktadır. KRK prognozu, evre ile ilişkilidir. Hastaların sadece \%40'ında erken evrede tanı konmaktadır. Tüm dünyada ve ülkemizde risk faktörleri göz önüne alınarak geliştirilen KRK tarama stratejileri ile tümörün erken evrede saptanması ve kansere bağlı morbidite ve mortalitenin azaltılması hedeflenmiştir.
Bu makalede Ege Üniversitesi Tıp Fakültesi Hastanesinde 1992-2017 yılları arasında kayıtı 7.285 KRK olgusunun epidemiyolojik ve genel sağ kalım özelliklerinin araştırılması amaçlanmıştır.

\section{Gereç ve Yöntem}

Ege Üniversitesi Kanserle Savaş Uygulama ve Araştırma Merkezi (EÜKAM) tarafından 19922017 yılları arasında toplanan KRK verileri CANREG özel bilgisayar programına kaydedilmiştir. Bu veriler WHO (Dünya Sağlık Örgütü) ve Surveillance, Epidemiology, and End Results (SEER) sistemleri temelinde evrelenip gruplanarak analizler yapılmıştır. Olgular, gastroenteroloji kliniğinde veya dışarıda tanı alıp, tedavileri hastanemizde yapılan KRK olgularıdır. Histolojik sınıflama WHO/IARC tümör sınıflamalarına göre verilmiştir (4). Seri içerisinde daha az oranda nöroendokrin tümör $(\% 0,7)$, lenfoma $(\% 0,5)$, malign melanom $(\% 0,3)$ ve mezenkimal tümör $(\% 0,3)$ tanısı alan olgular mevcuttur. Ancak baskın tümör grubunun karsinom grubu olgular (büyük oranda da adenokarsinom) olması ve nonepitelyal tümör grubunun istatistik farklılık yaratmaması nedeniyle tüm seri "Kolorektal kanserler (KRK)" başlığı altında incelenmiştir.

Evrelemede SEER ve TNM $/$ WHO tümör sınıflamaları dikkate alınmıştır (4). Buna göre; 
Evre 0: $T=$ Insitu $N=0 M=0$

Evre I (Lokal): $T=T 1-T 2, N=0, M=0$

Evre II (Lokal ileri): $\mathrm{T}=\mathrm{T} 3-\mathrm{T} 4, \mathrm{~N}=0, \mathrm{M}=0$

Evre III (Lokal ileri): $\mathrm{T}=$ Herhangi bir $\mathrm{T}$, $\mathrm{N}=\mathrm{N} 1-\mathrm{N} 2, \mathrm{M}=0$

Evre IV (Metastatik): $\mathrm{T}=$ Herhangi bir $\mathrm{T}$, $\mathrm{N}=$ Herhangi bir $\mathrm{N}, \mathrm{M}=1$ (TxNxM1 grup dahil)

olarak gruplanmıştır.

İstatistik analizlerde Ki-kare, General Linear Model (GLM), Kaplan Meier sağ kalım analizleri uygulanmıştır. Kaplan Meier sağ kalım analizinde LogRank (Mantel-Cox), Breslow (Generalized Wilcoxon) ve Tarone-Ware istatistikleri kullanılmıştır. İstatistik analizlerde $p<0,05$ istatistiksel olarak anlamlı kabul edilmiştir. Bu çalışma Ege Üniversitesi Tıbbi Araştırmalar Yerel Etik Kurulu tarafından onaylanmıştır (Tarih:21.08.2019, Karar numarası: 19-8.1T).

\section{Bulgular}

EÜKAM'a kayıtlı toplam 117.139 kanser olgusundan 7.285'i $(\% 6,2) \quad$ KRK'dir. Tüm kanserler içinde sıklık sırasına göre yedinci sırada yer almıştır. Cinsiyete göre bakıldığında, KRK erkeklerde yedinci ve kadınlarda altıncı en sık görülen tümördür. KRK olgularının 4.330'u
$(\% 59,4)$ erkek, 2.955 ’i $(\% 40,6)$ kadın olup cinsiyetler arası fark istatistiksel olarak anlamlıdır (ki-kare $=30,532 ; \quad p<0,001)$. En sık yerleşim yerleri, cinsiyet farkı saptanmaksızın, sırasıyla rektum $(n=2,794, \% 38,4)$, sigmoid kolon $(\mathrm{n}=1.185, \% 16,3)$ ve çekumdur $(\mathrm{n}=490, \% 6,7)$ (Tablo-1). Cinsiyetler arasında KRK yerleşim yerleri açısından istatistiksel olarak anlamlı bir fark saptanmamıştır.

Tüm yaş grupları içerisinde KRK yaş arttıkça artmaktadır. KRK'de cinsiyetlere göre yaş grupları incelendiğinde 60 yaş ve üzerinde her iki cinsiyette de anlamlı artış mevcuttur $(p=0,022)$. Cinsiyetler arası fark anlamlı bulunmamıştır $(p=0,299)$ (Şekil-1).

Son 25 yılda hastanemizde KRK'de artış izlenmiştir. Yıllara göre doğrusal artış toplamda anlamlıdır (GLM: $\quad \mathrm{F}=12,349 ; \quad \mathrm{p}<0,0001$ ). Cinsiyetler arasında fark istatistiksel olarak anlamlı bulunmamıştır $(p=0,299)$ (Şekil-2).

Kolorektal yerleşimli tümörlerin histolojik dağılımına bakıldığında olguların 6.297'si (\%86) adenokarsinom histolojisindedir. Kolorektal tümör histolojisinde cinsiyetler arasında istatistiksel olarak anlamlı fark saptanmamıştır $(p=0,350)$ (Tablo-2). Adenokarsinomlar içerisinde 66 (\%1) olguda taşlı yüzük hücreli tip, $619(\% 9,7)$ olguda müsinöz adenokarsinom izlenmiştir.

Tablo-1.Kolorektal kanserlerin kolon segmentlerinde cinsiyetlere göre dağılımı.

\begin{tabular}{|c|c|c|c|c|c|c|}
\hline \multirow{2}{*}{ Yerleşim Yeri } & \multicolumn{2}{|c|}{ Erkek } & \multicolumn{2}{|c|}{ Kadın } & \multicolumn{2}{|c|}{ Toplam } \\
\hline & $\mathbf{n}$ & $\%$ & $\mathbf{n}$ & $\%$ & $\mathbf{n}$ & $\%$ \\
\hline Çekum & 280 & 6,5 & 210 & 7,1 & 490 & 6,7 \\
\hline Appendiks & 25 & 0,6 & 34 & 1,2 & 59 & 0,8 \\
\hline Çıkan kolon & 197 & 4,5 & 176 & 6,0 & 373 & 5,1 \\
\hline Hepatik fleksura & 95 & 2,2 & 67 & 2,3 & 162 & 2,2 \\
\hline Transvers kolon & 114 & 2,6 & 84 & 2,8 & 198 & 2,7 \\
\hline Splenik fleksura & 95 & 2,2 & 43 & 1,5 & 138 & 1,9 \\
\hline İnen kolon & 153 & 3,5 & 130 & 4,4 & 283 & 3,9 \\
\hline Sigmoid kolon & 701 & 16,2 & 484 & 16,4 & 1185 & 16,3 \\
\hline Rektosigmoid bileşke & 238 & 5,5 & 129 & 4,4 & 367 & 5,0 \\
\hline Rektum & 1674 & 38,7 & 1120 & 37,9 & 2794 & 38,4 \\
\hline Aşan lezyon" & 39 & 0,9 & 22 & 0,7 & 61 & 0,8 \\
\hline Kolon, BBT & 719 & 16,6 & 456 & 15,4 & 1175 & 16,1 \\
\hline Toplam & 4.330 & 100,0 & 2.955 & 100,0 & 7.285 & 100,0 \\
\hline
\end{tabular}

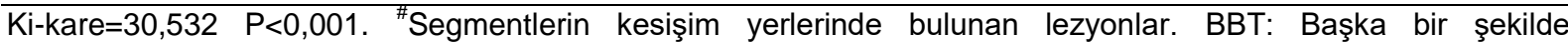
tanımlanmayan. 


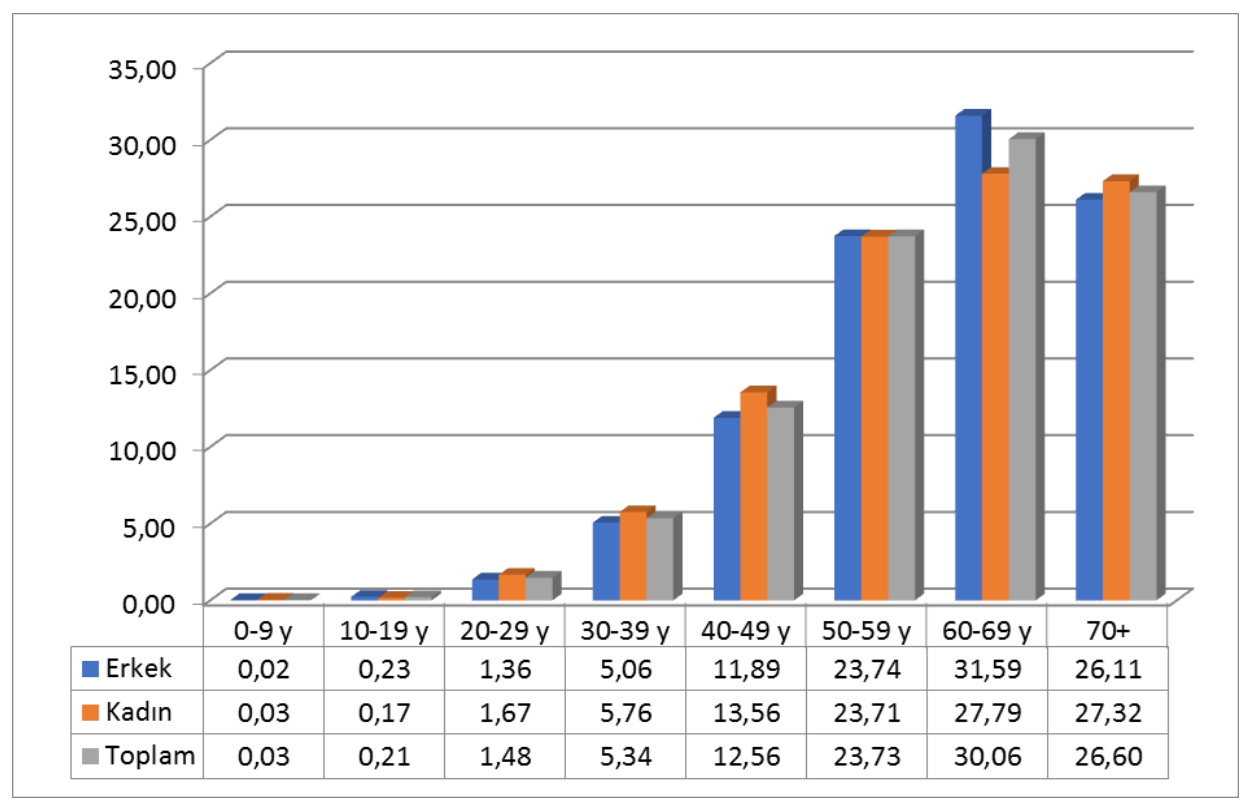

y: yaş, *Ki-kare:16,314 p=0,022

Şekil-1. Yaş gruplarına göre kolorektal kanserlerin oransal dağııımı.

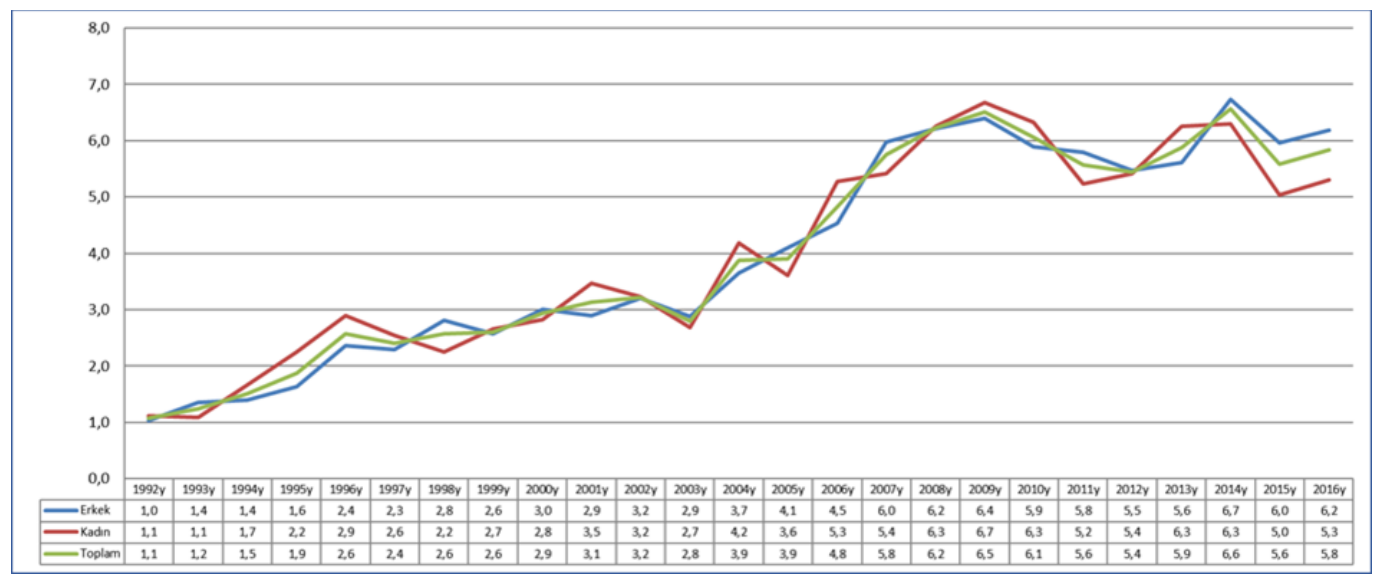

$y:$ yll. GLM: F=12,349; $p<0,0001$.

Şekil-2. Kolorektal kanser olgularının yıllara göre sayısal artı̧̧ çizelgesi.

Tablo-2. Kolorektal tümör histolojilerinin dağılımı.

\begin{tabular}{lcccccc}
\hline \multirow{2}{*}{ Histolojik tip } & \multicolumn{2}{c}{ Erkek } & \multicolumn{2}{c}{ Kadın } & \multicolumn{2}{c}{ Toplam } \\
\cline { 2 - 7 } & $\mathbf{n}$ & $\%$ & $\mathbf{n}$ & $\%$ & $\mathbf{n}$ & $\%$ \\
\hline Adenokarsinom & 3749 & 86,6 & 2548 & 86,2 & 6297 & 86,4 \\
Malign neoplazm, BBT & 336 & 7,8 & 217 & 7,3 & 553 & 7,6 \\
Karsinom, BBT $_{\text {Nöroendokrin tümör }}^{*}$ & 150 & 3,5 & 123 & 4,2 & 273 & 3,7 \\
Lenfoma & 33 & 0,8 & 19 & 0,6 & 52 & 0,7 \\
Skuamöz hücreli karsinom & 24 & 0,6 & 11 & 0,4 & 35 & 0,5 \\
Malign melanom & 10 & 0,2 & 21 & 0,7 & 31 & 0,4 \\
Sarkom & 15 & 0,3 & 9 & 0,3 & 24 & 0,3 \\
Toplam & 13 & 0,3 & 7 & 0,2 & 20 & 0,3 \\
\hline
\end{tabular}

Ki-kare $=14,121 \mathrm{P}=0,49$. ki-kare=14,121 p=0,49. *WHO-20104 sınıflamasına göre Nöroendokrin tümör, Evre I-II ve III'e karşוlık gelen tümörler, **yüksek riskli gastrointestinal stromal tümörler bu grup altında değerlendirilmiştir. BBT: Başka bir şekilde tanımlanmayan. 
Hastaların yarısından çoğunun $(\% 54,2)$ lokal ileri evrede tanı aldığı görülmüştür. Evre açısından cinsiyetler arasında istatiksel olarak anlamlı fark saptanmamıştır $(p=0,585)$. Lokalize tümörler içerisinde $67(\% 1,2)$ olgu karsinoma insitu olarak tanı almıştır. (Tablo-3, Şekil-3).

Tablo-3. Kolorektal kanserlerin cinsiyet ve evrelere göre dağılımı.

\begin{tabular}{lccc}
\hline \multicolumn{1}{c}{ Evre } & $\begin{array}{c}\text { Erkek } \\
\mathbf{n}(\%)\end{array}$ & $\begin{array}{c}\text { Kadın } \\
\mathbf{n}(\%)\end{array}$ & $\begin{array}{c}\text { Toplam } \\
\mathbf{n}(\%)\end{array}$ \\
\hline Lokalize Tümör & $583(16,9)$ & $384(16,4)$ & $967(16,7)$ \\
Lokal ileri evre & $1.843(53,5)$ & $1.296(55,3)$ & $3.139(54,2)$ \\
Uzak Yayılım Metastaz & $1.022(29,6)$ & $664(28,3)$ & $1.686(29,1)$ \\
Toplam & $.3448(100)$ & $2.344(100)$ & $5.792(100)$ \\
\hline
\end{tabular}

ki-kare: sig f: $1,938 \mathrm{p}=0,585$.

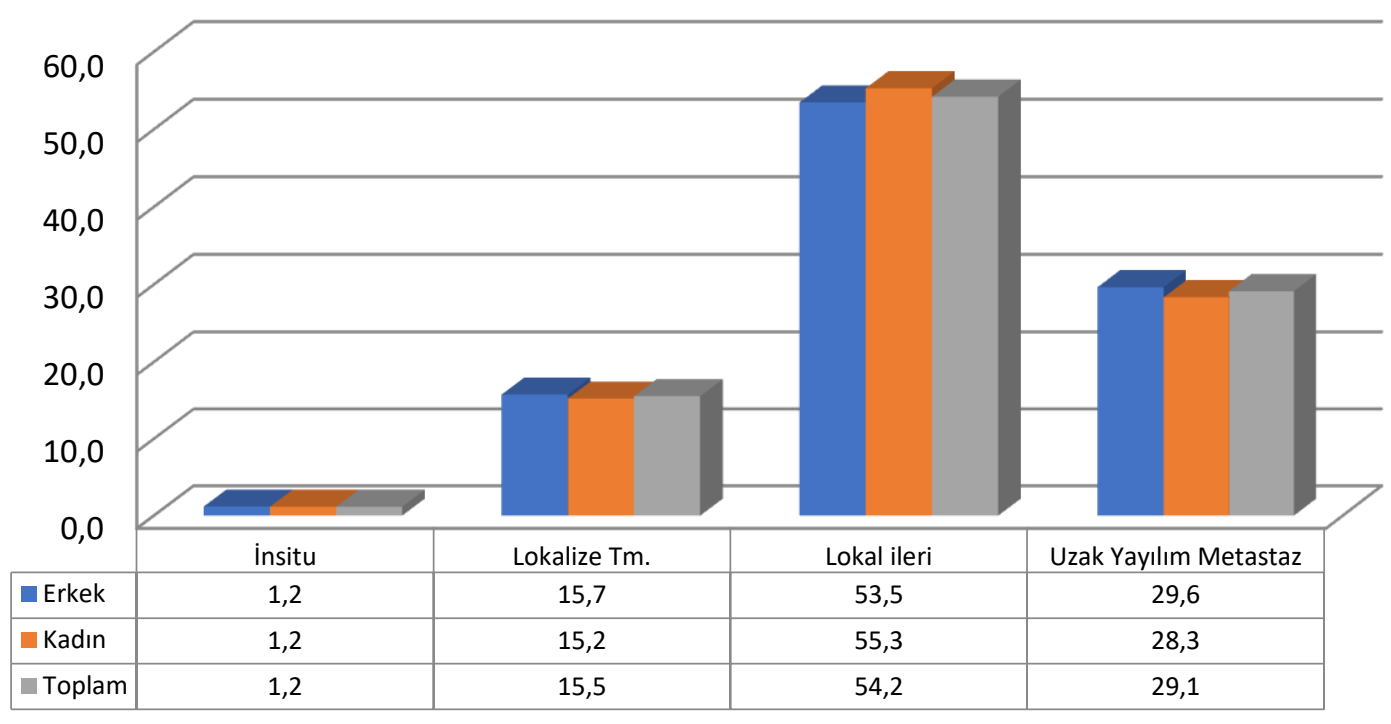

Şekil-3. Kolorektal kanserlerin cinsiyet ve evrelere göre dağılımı.

Olgularımızın ortalama sağ kalımı 69 ay, 5 ve 10 yıllık GSK oranları sırasıyla \%53 ve \%40'tır (Tablo-4, Şekil-4). Cinsiyetlere göre beş ve 10 yıllık GSK oranları erkeklerde sırasıyla \%51,2 ve \%37,8 kadınlarda ise sırasıyla \%55,6 ve \%43,3 saptanmıştır. Beş yıllık GSK'da cinsiyetler arası anlamlı farklılık saptanmazken, 10 yıllık GSK kadınlarda istatistiksel olarak anlamlı yüksek bulunmuştur (Tablo-4).

Tablo-4. Kolorektal kanserlerde cinsiyetlere göre beş ve 10 yıllık sağ kalım dağılımı.

\begin{tabular}{cccccc}
\hline Cinsiyet & $\mathbf{n}$ & Ölüm (n) & Yaşayan (\%) & $\begin{array}{c}\mathbf{5} \text { yıllık sağ kalım } \\
(\%)\end{array}$ & $\begin{array}{c}\text { 10 yıllık sağ kalım } \\
(\%)\end{array}$ \\
\hline Erkek & 3.319 & 1.876 & 43,5 & 51,2 & 37,8 \\
Kadın & 2.214 & 1.167 & 47,3 & 55,6 & 43,3 \\
Toplam & 5.533 & 3.043 & 45,0 & 53 & 40 \\
\hline
\end{tabular}

Yaş gruplarına göre beş ve 10 yıllık sağ kalım analizinde; en düşük GSK oranı 70 yaş ve üzeri grupta saptanmıştır. Yetmiş yaş ve üstü grup dikkate alınmazsa, 20-29 yaş grubunda da beş ve 10 yıllık GSK, istatistiksel olarak anlamlı düşük bulunmuştur $(p<0,0001)$. Yaş gruplarına göre 5-10 yıllık GSK dağılımı Tablo-5'te, kümülatif sağ kalım analizleri Şekil-5'te gösterilmiştir. 


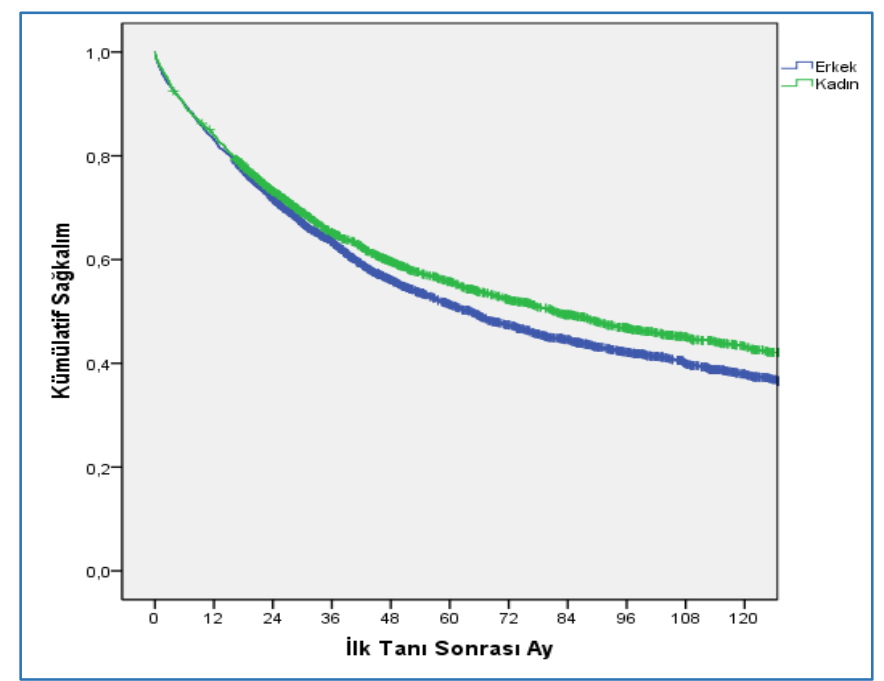

Şekil-4. Kolorektal kanserlerde cinsiyetlere göre beş ve 10 yıllık sağ kalım eğrisi.

Tablo-5. Kolorektal kanserlerde yaş gruplarına göre beş ve 10 yıllık sağ kalım dağılımı ve oranları.

\begin{tabular}{cccccc}
\hline Yaş Grubu & $\mathbf{n}$ & Ölüm $(\mathbf{n})$ & Yaşayan (\%) & $\mathbf{5}$ yıllık Sağ kalım (\%) & 10 yıllık Sağ kalım (\%) \\
\hline $\mathbf{0 - 9} \mathbf{y}$ & 1 & 0 & 100,0 & 100,0 & 100,0 \\
$\mathbf{1 0 - 1 9} \mathbf{y}$ & 7 & 3 & 57,1 & 71,4 & 53,5 \\
$\mathbf{2 0 - 2 9} \mathbf{y}$ & 62 & 34 & 45,2 & 48,8 & 41,3 \\
$\mathbf{3 0 - 3 9} \mathbf{y}$ & 267 & 119 & 55,4 & 61,1 & 54,2 \\
$\mathbf{4 0 - 4 9} \mathbf{y}$ & 675 & 309 & 54,2 & 62,2 & 50,2 \\
$\mathbf{5 0 - 5 9} \mathbf{y}$ & 1.365 & 662 & 51,5 & 58,6 & 46,1 \\
$\mathbf{6 0 - 6 9} \mathbf{y}$ & 1.659 & 868 & 47,7 & 54,5 & 41,0 \\
$\mathbf{7 0 y}$ üzeri & 1.496 & 1.048 & 29,9 & 40,2 & 25,8 \\
\hline
\end{tabular}

Wilcoxon (Gehan) $=238.262, p<0,0001$

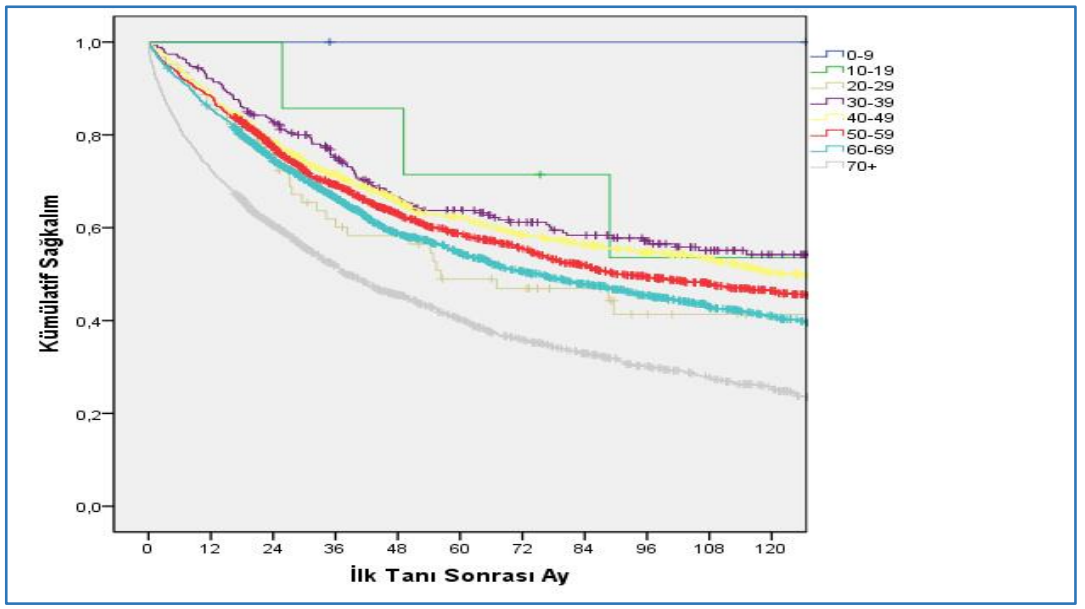

Şekil-5. Kolorektal kanserlerde yaş gruplarına göre Kaplan-Meier kümülatif sağ kalım grafiği.

Olgularımızda, sağ kalım ve histolojik tip arasında anlamlı ilişki bulunmuştur $(p<0,001)$. Malign melanom, skuamöz hücreli karsinom, sarkom ve "indiferan" malign neoplazmlarda (Malign neoplazm, başka bir şekilde tanımlanamayan) sağ kalım daha kötüdür. Lokal ileri evre kanserde beş yıllık sağ kalım \%66,4 iken uzak metastaz varlığında \%15,8'e düşmektedir ( $p<0,0001)$ (Tablo-6, Şekil-6). 
Tablo-6. Kolorektal kanserlerde histolojik tanıya göre sağ kalım dağılımı.

\begin{tabular}{lccccc}
\hline \multicolumn{1}{c}{ Histoloji } & $\mathbf{n}$ & Ölüm & Yaşayan & $\begin{array}{c}\text { 5 yıllık sağ } \\
\text { kalım }\end{array}$ & 10 yıl sağ kalım \\
\cline { 3 - 6 } & & $\mathbf{n}$ & $\mathbf{( \% )}$ & $\%$ & $\%$ \\
\hline Adenokarsinom & 4.843 & 2.707 & 44,1 & 54,7 & 42,5 \\
Malign neoplazm, BBT & 346 & 257 & 25,7 & 37,0 & 23,6 \\
Karsinom, BBT & 215 & 134 & 37,7 & 49,2 & 39,1 \\
Nöroendokrin tümör ${ }^{*}$ & 47 & 18 & 61,7 & 72,1 & 48,5 \\
Lenfoma & 26 & 9 & 65,4 & 68,5 & 62,6 \\
Skuamöz hücreli karsinom & 19 & 15 & 21,1 & 31,6 & 26,3 \\
Malign melanom & 11 & 9 & 20,0 & 27,3 & - \\
Sarkom & 15 & 12 & 20,0 & 32,7 & 16,4
\end{tabular}

BBT: Başka bir şekilde tanımlanmayan. *WHO-2010'a göre Nöroendokrin tümör, Evre I, II ve Ill'e karşlık gelen tümörler (Evre III= Nöroendokrin karsinom).

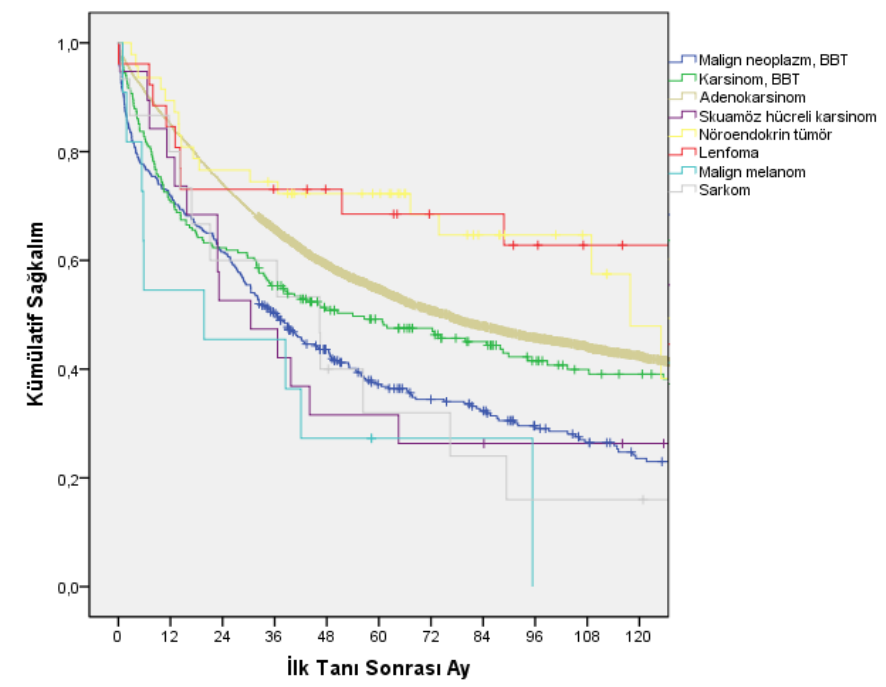

Şekil-6. Kolorektal kanserlerde histolojik tanıya göre sağ kalım eğrileri.

Sağ kolon ve sol kolon yerleşimli tümörlerde sağ kalım açısından fark saptanmamıştır $(p=0,180)($ Tablo-7, Şekil-7).

Tablo-7. Kolorektal kanserlerde lateralite ve sağ kalım özellikleri.

\begin{tabular}{|c|c|c|c|c|c|}
\hline \multirow{2}{*}{$\begin{array}{l}\text { Kolorektal tümör } \\
\text { yerleşim }\end{array}$} & \multirow{2}{*}{$\mathbf{n}$} & \multirow{2}{*}{$\underset{\text { Ölüm }}{\text { n }}$} & Yaşayan & 5 yıllık sağ kalım & 10 yıl sağ kalım \\
\hline & & & $(\%)$ & $\%$ & $\%$ \\
\hline Sağ kolon & 972 & 518 & 46,7 & 55,0 & 44,4 \\
\hline Sol Kolon & 3.602 & 2.016 & 44,0 & 55,4 & 42,7 \\
\hline
\end{tabular}

Tablo-8. Kolorektal kanserde evreye göre sağ kalım oranları.

\begin{tabular}{lccccc}
\hline Evre & $\mathrm{n}$ & Ölüm & Yaşayan & 5 Yıllık Sağ kalım & 10 Yıllık Sağ kalım \\
\hline Lokal & 786 & 229 & 70,9 & 77,7 & 62,4 \\
Lokal İleri & 2.374 & 1.041 & 56,1 & 66,4 & 51,5 \\
Metastatik & 1.344 & 1.136 & 15,5 & 16,0 & 9,2 \\
Toplam & 4.504 & 2.406 & 46,6 & - & - \\
Wilcoxon (Gehan)=1247,77 & p $<0,0001$ & & & & \\
\hline
\end{tabular}




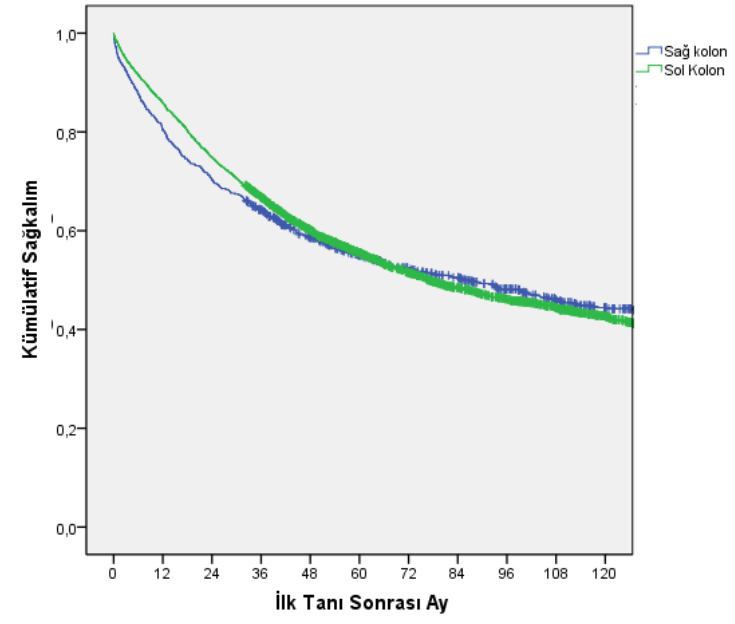

Şekil-7. Kolorektal kanserlerde lateralite ve sağ kalım grafiği.

KRK evrelerine göre GSK özellikleri Tablo-8 ve Şekil-8'de gösterilmiştir. Kümülatif sağ kalımda lokal evreyle, lokal ileri evre arasında istatistiksel olarak anlamlı fark saptanmıştır $(p=0,000)$. Lokal ileri evre ile metastatik evre arasındaki fark da istatistiksel olarak anlamlı bulunmuştur $(p=, .000)$. Evrelere göre sağ kalım oranları Tablo-8'de, sağ kalım eğrileri Şekil-8'de gösterilmiştir.

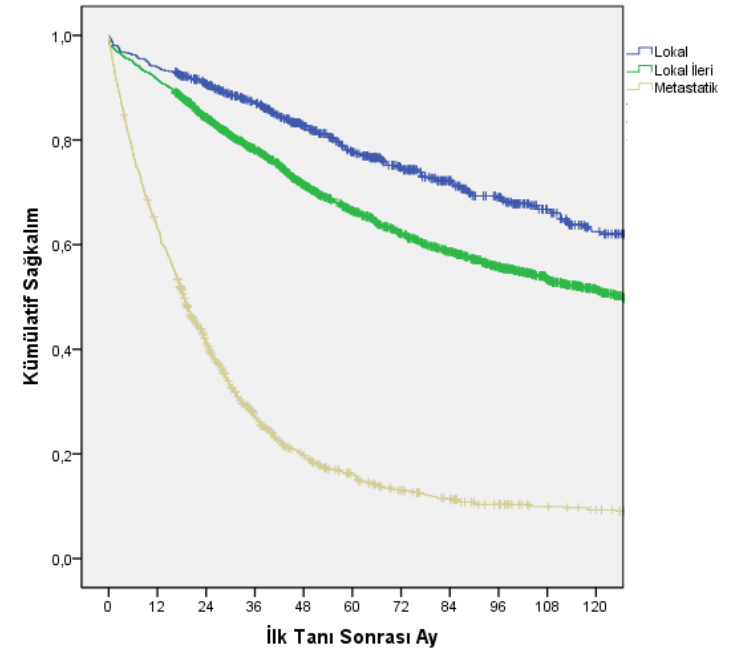

Şekil-8. Kolorektal kanserde evreye göre sağ kalım Eğrileri.

Tedavi verileri bulunan 5.842 hastanın, 545'nin $(\% 9,3)$ tedavi almadığı, 413'ünün $(\% 7)$ sadece kemoterapi, 57'sinin (\%) sadece radyoterapi, 81 'inin $(\% 1,4)$ kemoterapi ve radyoterapi kombine tedavi, 2.441 'inin $(\% 41,8)$ sadece cerrahi tedavi, 1.443'ünün (\%24,7) kemoterapi ve cerrahi kombine tedavi, 318'inin $(\% 5,4)$ cerrahi ve radyoterapi kombine tedavi ve 534'ünün $(\% 9,1)$ ise cerrahi, radyoterapi ve kemoterapi kombine tedavi aldıkları görülmüştür. Tüm serimizde tedavi verisi bulunan 5,842 hastanın, evrelere göre tedavi dağılımları Tablo-9'de gösterilmiştir.

Tablo-9. Kolorektal kanser hastalarının evrelere göre tedavi dağılımları.

\begin{tabular}{|c|c|c|c|c|c|c|c|c|c|c|c|c|c|c|c|c|c|c|}
\hline \multirow{2}{*}{ Evre } & \multicolumn{2}{|c|}{ Yapılmadı } & \multicolumn{2}{|c|}{$\mathrm{Kt}$} & \multicolumn{2}{|c|}{ Rt } & \multicolumn{2}{|c|}{$\mathrm{RT}+\mathrm{kt}$} & \multicolumn{2}{|c|}{ cerrahi } & \multicolumn{2}{|c|}{$\mathrm{ct}+\mathrm{kt}$} & \multicolumn{2}{|c|}{$\mathrm{ct}+\mathrm{rt}$} & \multicolumn{2}{|c|}{$\mathrm{ct}+\mathrm{rt}+\mathrm{kt}$} & \multicolumn{2}{|c|}{ Toplam } \\
\hline & $n$ & $\%$ & $\mathrm{n}$ & $\%$ & $\mathrm{n}$ & $\%$ & $\mathrm{n}$ & $\%$ & $\mathrm{n}$ & $\%$ & $\mathrm{n}$ & $\%$ & $\mathrm{n}$ & $\%$ & $\mathrm{n}$ & $\%$ & $\mathrm{n}$ & $\%$ \\
\hline Insutu & 25 & 4,6 & 1 & 0,2 & 1 & 1,8 & 0 & 0,0 & 37 & 1,5 & 2 & 0,1 & 0 & 0,0 & 1 & 0,2 & 67 & 1,1 \\
\hline Lokalize & 93 & 17,1 & 14 & 3,4 & 16 & 28,1 & 6 & 7,4 & 581 & 23,8 & 92 & 6,4 & 58 & 18,2 & 52 & 9,7 & 915 & 15,7 \\
\hline Lokal İleri & 88 & 16,1 & 23 & 5,6 & 23 & 40,4 & 32 & 39,5 & 1470 & 60,2 & 870 & 60,3 & 231 & 72,6 & 416 & 77,9 & 3159 & 54,1 \\
\hline Metastatik & 339 & 62,2 & 375 & 90,8 & 17 & 29,8 & 43 & 53,1 & 353 & 14,5 & 479 & 33,2 & 29 & 9,1 & 65 & 12,2 & 1701 & 29,1 \\
\hline Toplam & 545 & 100,0 & 413 & 100,0 & 57 & 100,0 & 81 & 100,0 & 2441 & 100,0 & 1443 & 100,0 & 318 & 100,0 & 534 & 100,0 & 5842 & 100,0 \\
\hline
\end{tabular}

Kt: kemoterapi, Rt: radyoterapi, ct: cerrahi tedavi.

\section{Tartışma}

Ege Üniversitesi Hastanesine kayıtlı olgular arasında 25 yıllık bir dönemi içeren 117.139 olguluk serimizden 7.285 'inin $(\% 6,2)$ KRK olduğu saptanmıştır. Dünya Sağlık Örgütünün, Dünya kanser istatistiklerinin yayınlandığı GLOBOCAN 2018 raporunda KRK insidansının tüm kanserler içinde sıklık olarak üçüncü, mortalite açısından ikinci sırada yer aldığı belirtilmiştir (1). Bu rapor sonuçlarına göre KRK her 10 kanser vakasından birinden sorumludur (1). Bu istatistiklere göre, Türkiye, KRK insidansı ve mortalitesi yüksek olan bölgeler arasındadır (1). Türkiye genelinde Sağlık Bakanlığı 2010 verilerine göre, KRK kadın ve erkeklerde üçüncü sırada yer almaktadır (1). Bizim serimizde KRK sıklığı, tüm kanserler içinde yedinci sıradadır, cinsiyete göre KRK sıklığı, erkeklerde yedinci, kadınlarda altıncı sırada yer almış olup KRK sıklığının Türkiye verilerine göre daha alt sıralarda yer aldığı görülmüştür. Son yıllarda yayınlanan çalışmalarda Akdeniz tipi 
beslenme alışkanlığının KRK riskini azalttığı bildirilmiştir $(6,7)$. Ege bölgesinde Akdeniz tipi beslenme alışkanlığı yaygındır. Serimizde KRK'in yedinci sırada yer almasında beslenme alışkanlığının rol oynayabileceği düşünülmüştür. Her ne kadar uzun bir süre içinde kaydedilen, olgu sayısı yüksek bir seri olsa da tek merkez deneyimi olduğu ve tüm Ege bölgesini yansıtamayacağı dikkate alınmalıdır.

Olgularımızın \%59,4'ü erkek, \%40,6'sı kadındır. Daha önce yapılan çalışmalarda da serimizle benzer şekilde KRK sıklığının erkeklerde daha fazla olduğu gösterilmiştir (8-10). Bu durum biyolojik ve cinsiyete bağlı davranışlarla ilişkilendirilmiştir. Erkeklerde KRK kanser riskini artıran davranışlar yani kırmızı ve işlenmiş et tüketimi, sigara ve alkol kullanımı, viseral yağlanma kadınlara göre daha fazladır (3).

$\mathrm{Bu}$ çalışmada, yaş grupları incelendiğinde KRK sıklığının yaşla arttığı görülmüştür. Cinsiyetlere göre yaş grupları incelendiğinde, 60 yaş ve üzerinde KRK görülme sıklığı artmaktadır ve bu artış her iki cinsiyette de istatistiksel olarak anlamlı bulunmuştur $(p=0,022)$. Cinsiyetler arası fark saptanmamıştır $(p=0,299)$. KRK gelişiminde, adenom-kanser sekansının 10 yıla yayıldığı bilinmektedir. Pek çok kılavuz tarafından ortalama riskli bireylerde taramaya başlama yaşı 50 yaş kabul edilmektedir (11). Bizim serimizde de 60 yaşla birlikte KRK sıklığında anlamlı artış saptanması, 50 yaşla taramaya başlama önerisini desteklemiştir.

KRK'ye bağlı sağ kalım oranları tüm dünyada değişkenlik göstermektedir. Amerika'da tüm evreler için kolon kanserlerinde beş yıllık sağ kalım \%64 iken (12), bu oran erken evrede \%90'lara ulaşmaktadır. Avrupa'da beş yıllık sağ kalım oranları \%57 iken (10), Asya ülkelerinde \%31-\%62 arasında değişmektedir (13-15). Bizim serimizde olgularımızın yarısından fazlasına lokal ileri evrede tanı konmuştur. Çalışmamızda beş ve 10 yıllık GSK oranları sırasıyla \%53 ve \%40'tır. Dikkat çekici olarak lokal evrede 10 yıllık GSK oranı \%62 iken, metastatik evrede bu oranın \%9'a düştüğü görülmüştür. Sonuçlarımız literatür bilgileriyle benzerlik göstermekte ayrıca KRK'de tümörün erken evrede saptanmasının prognozdaki önemini vurgulamaktadır.

Merkezimizin 25 yıllık verilerinde, KRK insidansında yıllar içinde doğrusal artış izlenmiştir. Türkiye'de de durum benzerdir, ancak bu artışta kanser kayıtçılığında son yıllarda kaydedilen ilerlemenin de rolü olduğu göz ardı edilmemelidir (5). GLOBOCAN verileri kullanılarak, yıllar içerisinde KRK insidans ve KRK'ya bağlı mortalite sonuçlarının araştırıldığı bir çalışmada; bazı ülkelerde her ikisinin birden arttığı, bazılarında insidans artarken mortalitenin düştüğü, Amerika, Japonya ve Fransa gibi ülkelerde ise her ikisinin de azaldığı rapor edilmiştir (16). KRK insidans ve mortalitesindeki azalma, özellikle insan gelişmişlik indeksi çok yüksek olan ülkelerde, KRK tarama programlarının aktif bir şekilde hayata geçirilmesi, postoperatif mortalitenin azaltılması ve daha etkin tedavi yaklaşımlarının kullanılmasıyla ilişkilendirilmiştir.

\section{Sonuç}

Sonuç olarak, Ege Üniversitesi Tıp Fakültesi Hastanesinde, EÜKAM tarafından 1992-2017 arasında, 117.139 kanser kaydı gerçekleştirilmiş olup bunların 7.285'inin KRK olduğu saptanmıştır. KRK de hastanemizde yıllara göre artış vardır ve genellikle lokal ileri evrede tanı konulmaktadır. En sık görülme yaşı olan 60-69 yaş grubu için, 5 yıllık GSK oranı \%54,5 olarak bulunmuştur. On yıllık GSK oranı kadınlarda $\% 43,3$ olup erkeklerden daha yüksektir. Prognozda histoloji ve evre en belirleyici parametrelerdir.

Katkıda bulunanlar: $\mathrm{Bu}$ çalışmada kullanılan verilerde, derginin bu sayısının önsözünde "Teşekkür Listesinde" belirtilen tüm Ege Üniversitesi Tıp Fakültesi Gastroenteroloji Bilim Dalı, Patoloji Anabilim Dalı, Genel Cerrahi Anabilim Dalı, Medikal Onkoloji Bilim Dalı ve Radyasyon Onkolojisi Anabilim Dalı öğretim üyelerinin katkıları olmuştur.

\section{Kaynaklar}

1. Bray, F, Ferlay J, Soerjomataram I, Siegel RL., Torre LA and Jemal A. Global cancer statistics 2018: GLOBOCAN estimates of incidence and mortality worldwide for 36 cancers in 185 countries. CA: A Cancer Journal for Clinicians, 2018;68:394-424.

2. Magalhaes B, Peleteiro B, Lunet N. Dietary patterns and colorectal cancer: systematic review and metaanalysis. Eur J Cancer Prev. 2012;21:15-23. 
3. Bates B, Cox L, Nicholson S, et al. National Diet and Nutrition Survey: Results from Years 5 and 6 (combined) of the Rolling Programme (2012/2013-2013/2014) London: Public Health England; 2016.

4. Bosman, F.T. WHO Classification of Tumours of the Digestive System. World Health Organization Classification of Tumours, 4th Edition, International Agency for Research on Cancer, Lyon.

5. Sağlık Bakanlığı, Kanserle Savaş Dairesi Başkanlığı, Türkiye 2010 Kanser İstatistikleri, www.kanser.gov.tr.

6. Farinetti A, Zurlo V, Manenti A, Coppi F, Mattioli AV. Mediterranean diet and colorectal cancer: A systematic review. Nutrition. 2017 Nov - Dec;43-44:83-8.

7. Jones P, Cade JE, Evans CEL, Hancock N, Greenwood DC. The Mediterranean diet and risk of colorectal cancer in the UK Women's Cohort Study. Int J Epidemiol. 2017 Dec 1;46(6):1786-96.

8. Murphy G, Devesa SS, Cross AJ, Inskip PD, McGlynn KA, Cook MB. Sex disparities in colorectal cancer incidence by anatomic subsite, race and age. Int J Cancer. 2011;128(7): 1668-75.

9. White A, Ironmonger L, Steele RJC, Ormiston-Smith N, Crawford C, Seims A. A review of sex-related differences in colorectal cancer incidence, screening uptake, routes to diagnosis, cancer stage and survival in the UK. BMC Cancer. 2018;18(1):906.

10. EC. The State of Men's Health in Europe Report (Extended report) Luxembourg: European Commission; 2011.

11. Wolf AM, Fontham ET, Church TR, et al. Colorectal cancer screening for average-risk adults: 2018 guideline update from the American Cancer Society. CA: A Cancer Journal for Clinicians, 2018;68:250-81.

12. American Cancer Society. Cancer Facts \& Figures 2019. Atlanta, Ga: American Cancer Society; 2019.

13. De Angelis R, Sant M, Coleman MP, et al. Cancer survival in Europe 1999-2007 by country and age: results of EUROCARE-5 - a population-based study. LancetOncol 2014;15:23-34.

14. Yeole BB, Sunny L, Swaminathan R, Sankaranarayanan R, Parkin DM. Population-based survival from colorectal cancer in Mumbai, (Bombay) India. Eur J Cancer. 2001Jul; 37(11):1402-8.

15. Park YJ, Park KJ, Park JG, Lee KU, Choe KJ, Kim JP. Prognostic factors in 2230 Korean colorectal cancer patients: analysis of consecutively operated cases. World J Surg. 1999 Jul; 23(7):721-6.

16. Arnold M, Sierra MS, Laversanne M, et al. Global patterns and trends in colorectal cancer incidence and mortality Gut 2017;66:683-91. 